\title{
Protein kinase N1 promotes proliferation and invasion of liver cancer
}

\author{
XIA WANG ${ }^{1}$, YANSONG GE ${ }^{2}$, MINGQI SHI ${ }^{2}$, HANHAN DAI $^{2}$, WEI LIU ${ }^{2}$ and PEIYUAN WANG ${ }^{2}$ \\ ${ }^{1}$ Department of Pathology, Binzhou Medical University, Yantai, Shandong 264003; ${ }^{2}$ Department of Radiology, \\ Yantai Affiliated Hospital of Binzhou Medical University, Yantai, Shandong 264100, P.R. China
}

Received March 11, 2020; Accepted March 22, 2021

DOI: $10.3892 /$ etm.2021.10083

\begin{abstract}
Protein kinase (PK) N1, also called PKC-related protein 1, participates in the proliferation, invasion and metastasis of various malignant tumors. However, the role of PKN1 in liver cancer remains to be elucidated. The present study investigated the expression of PKN1 using immunohistochemistry in surgical specimens from 36 patients and analyzed the correlation with VEGF, microvascular density (MVD), cell proliferation index (Ki67) and clinicopathological parameters. PKN1 was highly expressed in hepatocellular carcinoma (HCC) and was positively correlated with histological grading of HCC, Ki67 expression and MVD. PKN1 expression in moderately and poorly differentiated HCC was significantly higher compared with highly differentiated HCC. Expression of PKN1 was positively correlated with Ki67 and MVD, and Ki67 expression was positively correlated with MVD. The effects of PKN1 on proliferation, invasion and apoptosis of liver cancer cells were detected in vitro. Cell viability, migration and invasion were reduced and the apoptosis rate was significantly improved when PKN1 expression was silenced in liver cancer cells. Thus, PKN1 serves an important role in the development and progression of liver cancer. Inhibition of PKN1 activity may provide a promising therapeutic target for liver cancer.
\end{abstract}

\section{Introduction}

Liver cancer is one of the commonest malignant tumors worldwide. In 2018, the estimated global incidence was $\sim 841,000$, with $\sim 782,000$ related deaths, while the incidence in China

Correspondence to: Professor Xia Wang, Department of Pathology, Binzhou Medical University, 346 Guanhai Road, Yantai, Shandong 264003, P.R. China

E-mail: wangxia7512@163.com

Professor Peiyuan Wang, Department of Radiology, Yantai Affiliated Hospital of Binzhou Medical University, 717 Jinbu Road, Yantai, Shandong 264100, P.R. China

E-mails: wangpeiyuan1640@163.com

Key words: protein kinase N1, liver cancer, microvascular density, proliferation accounts for $\sim 55 \%$, with 110,000 deaths every year (1-3). Currently, there are a variety of treatment options for liver cancer at different stages, including routine options (such as hepatectomy and transcatheter arterial chemoembolization), molecular targeted therapy (VEGF/VEGF monoclonal antibody, EGF receptor inhibitors) and immunotherapy (programmed death-1/programmed death-ligand 1), which can prolong the survival time and prognosis of some patients (4-6). However, due to the selection of indications, sensitivity to treatment and other reasons, most patients have not received effective treatment. Therefore, it is important to explore the mechanism of proliferation, invasion and metastasis of liver cancer. In recent years, research on PKN1 in tumors has attracted much attention and PKN1 has been reported as a promising therapeutic target for prostate cancer $(7,8)$. However, the role of PKN1 in liver cancer remains to be elucidated.

PKN1, also known as PKC-related protein 1, is a serine/threonine protein kinase belonging to the $\mathrm{PKC}$ superfamily (9). It is reported that PKN1 may participate in cytoskeletal reconstruction, cell adhesion, apoptosis, tumor cells and other life processes (10-12). Overexpression of PKN1 serves an important role in the development of neurodegenerative diseases, prostate cancer, ovarian cancer, endometrial cancer and other tumors $(9,13-16)$. PKN1 contains a unique regulatory domain in the amino terminus, which presents a loop of serine/threonine protein kinase that serves a key role in activation of PKN1. PKN1 can act upstream of mitogen-activated PKs, C-Jun N-terminal kinase and p38, or downstream of EGF signaling and TGF- $\beta(12,16,17)$. Activated PKN1 regulates the invasion of prostate cancer cells and phosphorylation of $\mathrm{p} 38$, which further regulates a signaling cascade of invasion-related genes PXN, NEDD9 and NT5E/CD73 (8). Yang et al (18) demonstrated that PKN1, as an important member of PI3K/AKT/mTOR signaling pathway, affects the differentiation of prostate adenocarcinoma cells and is closely associated with Gleason score. Inhibition of PKN1 blocks transcriptional activation in androgen-dependent cancer cells (7). In endometrial cancer cells, PKN1 modulates TGF- $\beta$ and EGF-dependent regulation of cell proliferation, migration and invasiveness and therefore is a component of the network signaling downstream of TGF- $\beta$ and EGF (15). James et al (19) demonstrated that inhibition of PKN1 expression stimulates apoptosis in malignant melanoma cells by regulating the WNT/ $\beta$-catenin pathway. 
In the present study, the expression of PKN1 in surgical specimens was investigated by immunohistochemistry and the correlation with VEGF, MVD, Ki67 index and clinicopathological parameters was analyzed. At the same time, the effects of PKN1 on the proliferation, invasion and apoptosis of liver cancer cells were detected in vitro and the role of PKN1 in liver cancer progression was further explored.

\section{Materials and methods}

Patients and specimens. A total of 36 patients with hepatocellular carcinoma (HCC) who were treated at Binzhou Medical University Hospital were enrolled. Patients who had received preoperative radiotherapy or chemotherapy or had tumors of other sites were excluded. Complete clinical and pathological data were recorded and hepatectomy specimens were collected by the Pathology Department of the Hospital. There were 27 males and 9 female patients, with a mean age of $58.8 \pm 9.6$ years (range 36-77 years). The study was approved by the Ethics Committee of Binzhou Medical University (Yantai, China; approval no. 2018-012) as required by the Declaration of Helsinki. Prior to sample collection, written consent to use their tissues was obtained from all patients.

The present study is a retrospective study and all 36 patients had single lesions, including 13 in the left hepatic lobe and 23 in the right hepatic lobe, and adjacent normal tissue was also obtained from the patients. The longest diameter ranged from $2 \mathrm{~cm}$ to $13 \mathrm{~cm}$, with an average of $6.6 \pm 3.4 \mathrm{~cm}(<6.6 \mathrm{~cm}$ in 23 cases and $\geq 6.6 \mathrm{~cm}$ in 13 cases). Histological grading of HCC was divided into well-differentiated (grade $\mathrm{I} ; \mathrm{n}=7$ ), moderately differentiated (grade II and III; $\mathrm{n}=21$ ) and poorly differentiated (grade IV; $\mathrm{n}=8$ ) according to Edmondson-Steiner grading system $(20,21)$.

Immunohistochemistry. All samples of pathological specimens were fixed in $4 \%$ paraformaldehyde for $24 \mathrm{~h}$ at room temperature, followed by gradient dehydration and paraffin embedding; $4-\mu \mathrm{m}$ sections were prepared for immunohistochemical staining. The sections were incubated with $0.01 \mathrm{~mol} / 1$ citrate buffer $\left(\mathrm{pH} \mathrm{6.0)}\right.$ in a microwave oven at $98^{\circ} \mathrm{C}$, three times for $5 \mathrm{~min}$, for antigen retrieval. Endogenous peroxidase was blocked by treatment with $3 \% \mathrm{H}_{2} \mathrm{O}_{2}$ for $20 \mathrm{~min}$ at room temperature. After pretreatment with normal goat serum (OriGene Technologies, Inc.) for $30 \mathrm{~min}$ at room temperature to block nonspecific binding, the sections were incubated with rabbit anti-PKN1 polyclonal antibody (cat. no. bs-7478R; BIOSS; 1:500), rabbit anti-VEGF polyclonal antibody (cat. no. 190031; ProteinTech Group, Inc.; 1:500) and rabbit anti-Ki67 ready-to use antibody (cat. no. ZM-0167; OriGene Technologies, Inc.; 1:100) and rabbit anti cluster of differentiation (CD)34 ready-to use antibody (cat. no. ZM-0046; OriGene Technologies, Inc.) overnight at $4^{\circ} \mathrm{C}$. Negative control was obtained by replacing the primary antibody with phosphate-buffered saline. Biotinylated goat anti-rabbit immunoglobulin G (cat. no. ZB-2301; OriGene Technologies, Inc.; 1:500) was applied as a secondary antibody for $30 \mathrm{~min}$ at $37^{\circ} \mathrm{C}$. The peroxidase reactivity was visualized by the application of 3,3'-diaminobenzidine solution (OriGene Technologies, Inc.) for $5 \mathrm{~min}$. Finally, the sections were counterstained with hematoxylin for $2 \mathrm{~min}$ at room temperature.
The necrotic area and severe inflammatory area were avoided in the selection of liver cancer specimens and significant areas of expression were selected for analysis. The immunoreactivity of PKN1 and VEGF was evaluated according to integral optical density (IOD) by Image-Pro Plus 6.0 (Media Cybernetics, Inc.). Ki67 proliferation index was calculated with Image Pro Plus 6.0 as follows: Ki67 $(\%)=$ positive tumor cells/all tumor cells x100\%. MVD was marked by CD34 (a classic endothelium marker). The mean number of stained microvessels was recorded from five unduplicated high-power fields (magnification, x400) per specimen.

Cells culture and reagents. The human liver cancer cell lines (HepG2 and Hep3B) were purchased from the cell banks of the Chinese Academy of Science and were cultured in Dulbecco's modified Eagle medium (DMEM) with high glucose (HyClone; Cytiva) and 10\% fetal bovine serum (FBS; Gibco; Thermo Fisher Scientific, Inc.) at $37^{\circ} \mathrm{C}$ in a humidified atmosphere with $5 \% \mathrm{CO}_{2}$. Then, three siRNAs against PKN1 were designed (19) and synthesized by Shanghai GenePharma Co., Ltd.: siPKN1-1: 5'-CCUCGAAGAUUUCAAGUUC-3'; siPKN1-2: 5'-GAACAUGAUCCAGACCUACAGCAAU-3'; siPKN1-3: 5'-ACAGUAAGACCAAGAUUGA-3'; and Negative control (NC) group 5'-UUCUCCGAACGUGUCACGUTT-3'. HepG2 and Hep3B cells were seeded in six-well plates and transfected with 100 pmol siRNA using Lipofectamine ${ }^{\circledR} 2000$ (Thermo Fisher Scientific, Inc.). PKN1 expression was detected using western blotting to confirm transfection efficiency. Of the three siRNAs, the two more efficient silencing sequences were selected for the following assays.

Reverse transcription-quantitative (RT-q)PCR. Total RNA (24h after transfection) of liver cancer cells was isolated with RNAiso plus reagent (Takara Biotechnology Co., Ltd.) and cDNA was generated with a PrimeScript RT Reagent kit with gDNA Eraser (Takara Biotechnology Co., Ltd.). Quantitative gene expression was performed for PKN1 and GAPDH (internal control) by LightCycler 480 SYBR-Green I Master Mix Reagent kit and the LightCycler 480 real-time System (Roche Diagnostics). Nucleotide sequences of specific primer for genes were as follows: PKN1 forward, 5'-AAAGCAGAAGCCGAGAACAC-3' and reverse, 5'-ACACAGCCAACTCCAGTTCC-3'; GAPDH forward, 5'-GAAGGTGAAGGTCGGAGTC-3' and reverse, 5'-GAAGATGGTGATGGGATTTC-3'. PCR amplification was performed under the following conditions: Initial denaturation for $10 \mathrm{~min}$ at $96^{\circ} \mathrm{C}$, followed by 40 cycles at $95^{\circ} \mathrm{C}$ for $15 \mathrm{sec}$ and $60^{\circ} \mathrm{C}$ for $60 \mathrm{sec}$. For each sample, the data was normalized to GAPDH to obtain ${ }^{\Delta} \mathrm{C}_{\mathrm{t}}$ and calculated using the $2^{-\Delta \Delta \mathrm{Cq}}$ method (22). Gene silencing rate $(\%)=\left(1-2^{\Delta \Delta \mathrm{Cq}}\right) \times 100 \%$.

Western blotting. Cellular proteins were collected $72 \mathrm{~h}$ after transfection and lysed with RIPA lysis buffer and phenylmethanesulfonyl fluoride (Beyotime Institute of Biotechnology). A BCA Protein Assay kit (cat. no. P0010; Beyotime Institute of Biotechnology) was used to detect protein concentration. Protein samples ( $40 \mu \mathrm{g} /$ lane) were separated by $12 \%$ SDS-PAGE and transferred to polyvinylidene fluoride membranes. Membranes were blocked with $5 \%$ skimmed milk in TBST buffer (TBS with $0.1 \%$ Tween-20) for $2 \mathrm{~h}$ at room temperature to avoid non-specific staining, then incubated with primary 
antibody overnight at $4^{\circ} \mathrm{C}$ and HRP-conjugated secondary antibodies (cat. no. ZB-2301; OriGene Technologies, Inc.; 1:50,000) for $30 \mathrm{~min}$ at $37^{\circ} \mathrm{C}$. Primary antibodies used were as follows: PKN1 (cat. no. ab231038; Abcam; 1:500) and GAPDH (cat. no. sc-25778; Santa Cruz Biotechnology, Inc.; 1:5,000). Protein bands were visualized by enhanced ECL chemiluminescence (Beyotime Institute of Biotechnology). IOD values were measured with the Image-Pro Plus 6.0 system (Media Cybernetics, Inc.).

Cell proliferation assay. Proliferation of HepG2 and Hep3B cells was detected using Cell Counting Kit-8 (CCK-8; Biosharp Life Sciences). Cells were seeded in a 96-well plate at a density of $5 \times 10^{3}$ cells/well and incubated for 0,24 and $48 \mathrm{~h}$. Cells were incubated for $1 \mathrm{~h}$ and OD at $450 \mathrm{~nm}$ was measured using an automatic spectrophotometer (SpectraMax M2; Molecular Devices, LLC). Cell viability was calculated based on OD values using the following equation: Cell viability $=\mathrm{OD}_{\text {test group }} / \mathrm{OD}_{\text {control group }} \mathrm{x} 100 \%$. Experiments were performed in triplicate.

Colony formation assay. HepG2 and Hep3B cells were seeded into six-well plates $\left(5 \times 10^{3}\right.$ cells/well) at $24 \mathrm{~h}$ after transfection and incubated with 10\% FBS DMEM for 10 days. Cells were stained with $0.1 \%$ crystal violet staining solution (G1064; Solarbio) for $20 \mathrm{~min}$ and the number of colonies with $>50$ cells counted. Colony formation rate $(\%)=$ colony numbers/seeded cells $\times 100 \%$. Five random unduplicated fields were analyzed for each well and each experiment was performed in triplicate.

Wound scratch assay. Cells $\left(5 \times 10^{5}\right)$ were seeded in six-well plates and cultured for $24 \mathrm{~h}$ at $37^{\circ} \mathrm{C}$ with $5 \% \mathrm{CO}_{2}$. Mitomycin C $(10 \mu \mathrm{g} / \mathrm{ml})$ was added for $1 \mathrm{~h}$ before processing to eliminate the effect of cell proliferation. Horizontal lines were scratched with 20- $\mu$ l pipette tips and the wells were washed three times with PBS to remove the scratched-out cells at room temperature, then incubated with $1 \% \mathrm{FBS}$ DMEM at $37^{\circ} \mathrm{C}$ with $5 \% \mathrm{CO}_{2}(1)$. Images were captured at 0,12 and $24 \mathrm{~h}$ and measured the scratch healing ability of the cells with an Image-Pro Plus 6.0 system. Each experiment was performed in triplicate.

Cell invasion assay. Transwell chambers with 8-mm pores (Corning Inc.) were used to detect cell invasion ability. In the upper chambers, $5 \times 10^{4}$ cells were resuspended in $200 \mu \mathrm{l}$ serum-free DMEM after Matrigel was coated at the bottom of the upper portion at $4^{\circ} \mathrm{C}$ and incubated at $37^{\circ} \mathrm{C}$ for $2 \mathrm{~h}$. The lower portion of the chamber contained $500 \mu 1$ 10\% FBS DMEM. The cells were cultured at $37^{\circ} \mathrm{C}$ in $5 \% \mathrm{CO}_{2}$ for $24 \mathrm{~h}$. Cells traversing the Matrigel were fixed in 95\% anhydrous methanol for $15 \mathrm{~min}$ at room temperature, air-dried for 10 min and stained with $0.1 \%$ crystal violet (Beijing Solarbio Science \& Technology Co., Ltd.) for $20 \mathrm{~min}$ at room temperature. Each experiment was performed in triplicate.

Apoptosis assay. The Annexin V method was used to detect apoptosis. Cells were collected by trypsin digestion at $48 \mathrm{~h}$ after transfection. A suspension of $1 \times 10^{6}$ cells $/ \mathrm{ml}$ was made by $1 \mathrm{X}$ Binding Buffer. Next, $5 \mu 1$ Annexin V-fluorescein isothiocyanate was added, followed by $5 \mu \mathrm{l}$ propidium iodide for $15 \mathrm{~min}$ in the dark at room temperature. Fluorescence signals from at least 10,000 cells were evaluated using a flow cytometer (EPICS XL; Beckman Coulter, Inc.). FACSDiva version 6.1.3 software (BD Biosciences) was used to analyze and generated percentages in all of the quadrants. The mean percentage of apoptosis rate (early + late apoptotic cells) and standard deviation were calculated from three repeated assays.

Statistical analysis. All data were analyzed with SPSS 22.0 software (IBM Corp.). The values are presented as the mean \pm standard deviation. Tukey's post hoc test was performed following one-way ANOVA to analyze statistically the mean values among multiple groups and Student's $t$ test was used to compare the differences between two groups. Spearman rank test was used to verify the correlations. $\mathrm{P}<0.05$ was considered to indicate a statistically significant difference. GraphPad Prism version 5 (GraphPad Software) was used for charts.

\section{Results}

Correlation of PKN1 expression with VEGF, Ki67, MVD and clinicopathological parameters in HCC. The immunoreactivity of PKN1, VEGF, Ki67 and CD34 in all 36 HCC specimens was tested and expression was analyzed with Image Pro Plus 6.0. No significant differences were observed in patients' sex, age, or tumor location and size in PKN1, VEGF, Ki67 and MVD ( $P>0.05$; Table I). PKN1 was expressed in all HCC tissues (Fig. 1A and B) and its expression was positively correlated with tumor histological grading, while PKN1 expression in adjacent normal tissue was very weak. The IOD of PKN1 in moderately and poorly differentiated HCC was significantly higher compared with highly differentiated HCC $(\mathrm{P}<0.01)$, but no significant difference was observed between moderately and poorly differentiated HCC $(\mathrm{P}>0.05)$. The expression of VEGF in moderately and poorly differentiated HCC was significantly higher compared with highly differentiated tumor $(\mathrm{P}<0.05)$, which was in accordance with PKN1 expression (Fig. 1C and D). Correlation analysis of PKN1, VEGF, Ki67 expression and MVD in HCC demonstrated that expression of PKN1 was positively correlated with Ki67 $(\mathrm{P}<0.01 ; r=0.493)$ and MVD $(\mathrm{P}<0.01 ; r=0.442)$, and the expression of Ki67 (Fig. 1E and F) was positively correlated with MVD (Fig. 1G and H; P<0.01; $r=0.445$; Table II).

Acquisition of efficient silencing sequence. According to RT-qPCR ( $24 \mathrm{~h}$ after transfection), the efficient silencing sequences were siPKN1-2 and siPKN1-3, with a rate of gene silencing of $>75 \%$. Western blotting demonstrated that expression of PKN1 (72 h after transfection) was downregulated in the siPKN1-2 and siPKN1-3 groups (Fig. 2). Thus, two different efficient silencing sequences (siPKN1-2 and siPKN1-3) were confirmed to explore the following biological function of PKN1 in liver cancer cells.

Downregulated PKN1 expression suppresses proliferation of liver cancer cells. CCK-8 assay demonstrated that OD of HepG2 and Hep3B cells after transfection were significantly suppressed compared with the NC group, particularly at $48 \mathrm{~h}$ after transfection $(\mathrm{P}<0.01$; Fig. $3 \mathrm{~A})$. The colony formation assay demonstrated that downregulation of PKN1 in HepG2 and Hep3B cells inhibited the number of colonies 
Table I. Correlation of expression of PKN1, VEGF, Ki67 and MVD with clinicopathological parameters in HCC.

\begin{tabular}{|c|c|c|c|c|c|}
\hline Feature & $\mathrm{n}$ & PKN1, IOD & VEGF, IOD & $\begin{array}{c}\text { MVD, microvessel } \\
\text { number }\end{array}$ & Ki67 rate, $\%$, \\
\hline \multicolumn{6}{|l|}{ Age } \\
\hline$<59$ & 16 & $39,972.39 \pm 12,397.59$ & $52,774.82 \pm 10,833.22$ & $21.89 \pm 7.81$ & $35.86 \pm 13.52$ \\
\hline$\geq 59$ & 20 & $33,338.48 \pm 12,097.38$ & $52,392 \pm 12,905.93$ & $20.87 \pm 5.16$ & $32.57 \pm 15.95$ \\
\hline \multicolumn{6}{|l|}{ Sex } \\
\hline Male & 27 & $36,516.58 \pm 12,886.37$ & $53,665.35 \pm 12,464.26$ & $21.66 \pm 6.53$ & $34.95 \pm 15.97$ \\
\hline Female & 9 & $35,597.82 \pm 12,010.71$ & $49,252.54 \pm 9,718.765$ & $20.33 \pm 6.21$ & $31.31 \pm 10.92$ \\
\hline \multicolumn{6}{|c|}{ Tumor location } \\
\hline Left lobe & 13 & $34,161.05 \pm 10,294.14$ & $51,360.11 \pm 14,249.16$ & $19.57 \pm 7.24$ & $30.29 \pm 12.07$ \\
\hline Right lobe & 23 & $37,488.45 \pm 13,674.28$ & $53,241.56 \pm 10,575.52$ & $22.32 \pm 5.79$ & $36.15 \pm 16.02$ \\
\hline \multicolumn{6}{|l|}{ Tumor size } \\
\hline$<6.6 \mathrm{~cm}$ & 23 & $35,465.07 \pm 11,013.2$ & $54,168.92 \pm 12,992.34$ & $22.05 \pm 6.76$ & $36.31 \pm 14.26$ \\
\hline$\geq 6.6 \mathrm{~cm}$ & 13 & $37,740.88 \pm 15,181.86$ & $49,719.4 \pm 9,346.68$ & $20.04 \pm 5.70$ & $30.02 \pm 15.47$ \\
\hline \multicolumn{6}{|c|}{ Histological grading } \\
\hline Highly & 7 & $23,094.83 \pm 8,535.475$ & $42,483.76 \pm 9,727.804$ & $14.39 \pm 7.93$ & $21.56 \pm 4.77$ \\
\hline Moderately & 21 & $39,205.88 \pm 11,414.21^{b}$ & $53,875.5 \pm 10,686.89^{a}$ & $22.74 \pm 4.79^{b}$ & $34.42 \pm 14.71^{\mathrm{a}}$ \\
\hline Poorly & 8 & $40,167.58 \pm 11,444.56^{b}$ & $57,933 \cdot 17 \pm 12,515.03^{\mathrm{a}}$ & $23.68 \pm 4.91^{\mathrm{a}}$ & $43.95 \pm 13.80^{\mathrm{b}}$ \\
\hline
\end{tabular}

${ }^{\mathrm{a}} \mathrm{P}<0.05 ;{ }^{\mathrm{b}} \mathrm{P}<0.01$. The data are presented as the mean $\pm \mathrm{SD}$. PKN1, protein kinase N1; Ki67, cell proliferation index; MVD, microvascular density; HCC, hepatocellular carcinoma; IOD, integral optical density.

Table II. Correlation analysis of the expression of PKN1, VEGF, Ki67 and MVD in HCC.

\begin{tabular}{lcccc}
\hline & PKN1 & VEGF & MVD & Ki67 \\
\hline PKN1 & & & & \\
P-value & $/$ & 0.128 & $0.007^{\mathrm{b}}$ & $0.002^{\mathrm{b}}$ \\
$r$ & $/$ & 0.258 & 0.442 & 0.493 \\
VEGF & & & & \\
P-value & 0.128 & $/$ & 0.236 & 0.36 \\
$r$ & 0.258 & $/$ & 0.203 & 0.157 \\
MVD & & & & \\
P-value & $0.007^{\mathrm{b}}$ & 0.236 & $/$ & $0.007^{\mathrm{b}}$ \\
$r$ & 0.442 & 0.203 & $/$ & 0.445 \\
\hline
\end{tabular}

PKN1, protein kinase N1; Ki67, cell proliferation index; MVD, microvascular density; HCC, hepatocellular carcinoma.

$(\mathrm{P}<0.01$; Fig. 3B). These results indicated that downregulation of PKN1 expression suppresses viability and proliferation of liver cancer cells.

Downregulated PKN1 expression inhibits migration and invasion of liver cancer cells. To investigate the effects of PKN1 on migration and invasion of liver cancer cells, a wound scratch assay and Transwell invasion assay were performed. The wound scratch assay revealed that cell healing in the siPKN1 group was significantly slower compared with the NC group at $24 \mathrm{~h}$ after transfection $(\mathrm{P}<0.01$; Fig. $4 \mathrm{~A})$. The Transwell invasion assay demonstrated that downregulation of PKN1 significantly reduced invasion of HepG2 and Hep3B cells across the Matrigel $(\mathrm{P}<0.01$; Fig. 4B). These results suggest that PKN1 knockdown inhibits migration and invasion of liver cancer cells.

Downregulated PKN1 expression enhances apoptosis of liver cancer cells. To verify the effect of PKN1 silencing on apoptosis of liver cancer cells, the Annexin V method with flow cytometry was used, which demonstrated that the apoptosis rate of HepG2 and Hep3B cells transfected with siPKN1 was significantly higher compared with cells transfected with negative siRNA $(\mathrm{P}<0.01$; Fig. 5). This indicated that downregulation of PKN1 expression enhances apoptosis of liver cancer cells.

\section{Discussion}

With the advance of medical technology, the treatment of liver cancer has entered the era of precise and multi-disciplinary combination therapy. Currently, molecular targeted drugs such as sorafenib, regorafenib, lenvatinib and immune checkpoint inhibitors have prolonged the survival of some patients (23-26). However, for complex reasons, the prognosis of most liver cancer patients is still unsatisfactory (27). Abnormal activation or overexpression of oncogenes is closely associated with tumor occurrence and development. Elucidating the role of oncogenes is important for the prevention and treatment of liver cancer.

Recent studies have shown that abnormal PKN family expression is closely associated with the occurrence and development of many diseases $(8,9,13-16)$. The three subtypes PKN1, PKN2 and PKN3 are involved in many cellular processes, such as cytoskeletal remodeling and glucose transport and potential 


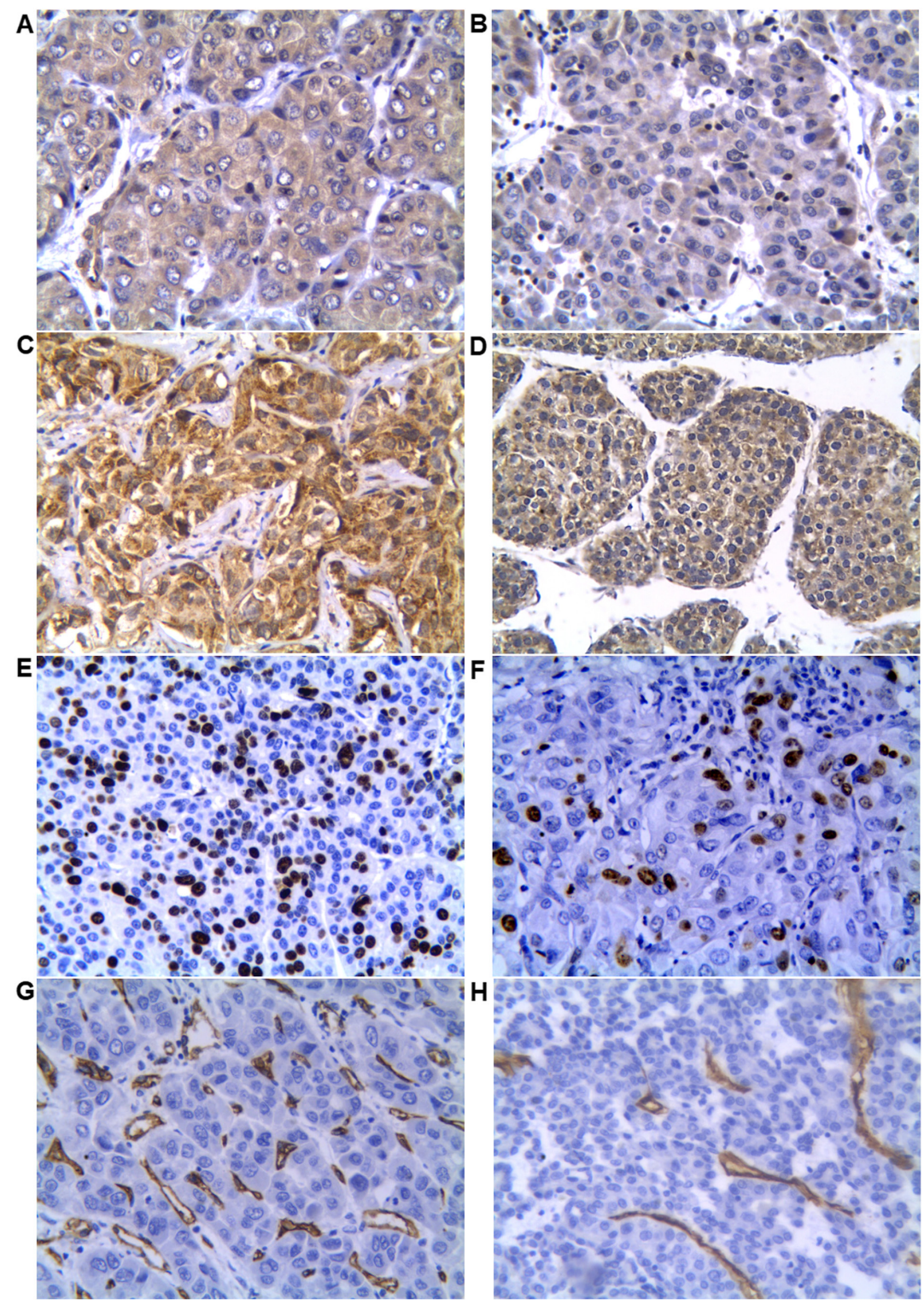

Figure 1. Expression of PKN1, VEGF, Ki67 and MVD distribution in HCC tissues (original magnification, x400). (A) PKN1 immunohistochemically staining located in cytoplasm demonstrated higher intensity in moderately differentiated HCC and (B) lower intensity in highly differentiated HCC. (C) VEGF expression in the cytoplasm shows higher intensity in poorly differentiated HCC and (D) lower in highly differentiated HCC. (E) Ki67 expression in the nucleus demonstrated higher proliferation index in poorly differentiated HCC and (F) lower index in highly differentiated HCC. MVD had higher distribution in (G) moderately differentiated HCC compared with (H) highly differentiated HCC. PKN1, protein kinase N1; Ki67, cell proliferation index; MVD, microvascular density; HCC, hepatocellular carcinoma.

roles served in neurodegeneration and cancer (11-13). As a major member of the PKN family, PKN1 gene is activated when cancer cells are hypoxic-ischemic, which can affect cell adhesion, regulate angiogenesis and influence invasion and metastasis $(7,8)$. In the present study, PKN1 expression was detected in the samples of all patients with HCC and expression was closely associated with the histopathological grading of HCC. PKN1 expression in moderately and poorly differentiated $\mathrm{HCC}$ was significantly higher compared with highly differentiated HCC. Some researchers have noted that the histological grading of HCC is an important prognostic factor after surgery and compared with low-grade $\mathrm{HCC}$, high-grade HCC is prognostic of a worse survival rate $(24,25)$.

Previous studies have shown that liver cancer is a highly vascularized malignant tumor and angiogenesis is a marker of tumor development $(26,28)$. MVD, an important indicator of tumor angiogenesis activity, can reflect the angiogenesis and distribution of tumors and is one of the markers for prediction of tumor progression and prognosis (29). Mukai et al (30) showed that PKN3 (an isoform of PKN family) knock-down induces a glycosylation defect of cell-surface glycoproteins, including intercellular adhesion molecule-1, integrin $\beta 1$ and integrin $\alpha 5$ in human umbilical vascular endothelial cells and the PKN3 knockout mice exhibited an impaired lung metastasis of melanoma cells. PKN3 inhibition increases its downstream target gene VE-cadherin levels and alters endothelial function, resulting in reduced colonization and micro-metastasis formation (31). Unfortunately, there have been few studies about PKN1 and tumor vascular endothelial activity. In the present study, the trend in expression of VEGF was similar to that of PKN1; both of which were significantly higher in moderately and poorly differentiated HCC compared with highly differentiated HCC. 


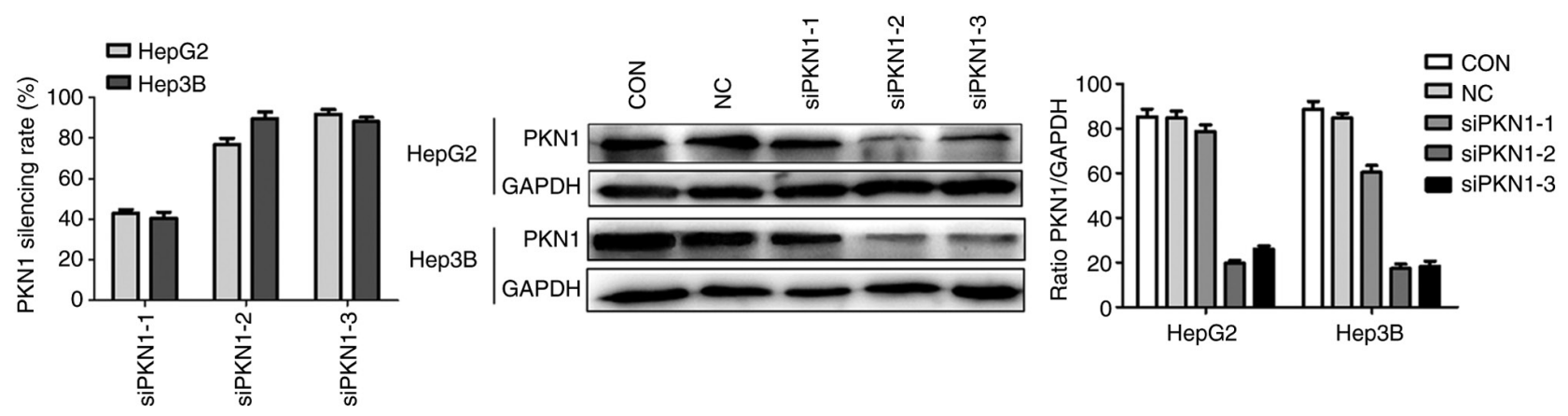

Figure 2. siPKN1-2 and siPKN1-3 were confirmed as efficient silencing sequences. PKN1 expression in HepG2 and Hep3B cell lines was detected by reverse transcription-quantitative PCR and western blotting following transfection with siPKN1-1, siPKN1-2 and siPKN1-3 sequences. It was determined that siPKN1-2 and siPKN1-3 were efficient silencing sequences to perform the following experiments. si, short interfering; PKN1, protein kinase N1; CON, control; $\mathrm{NC}$, negative control.
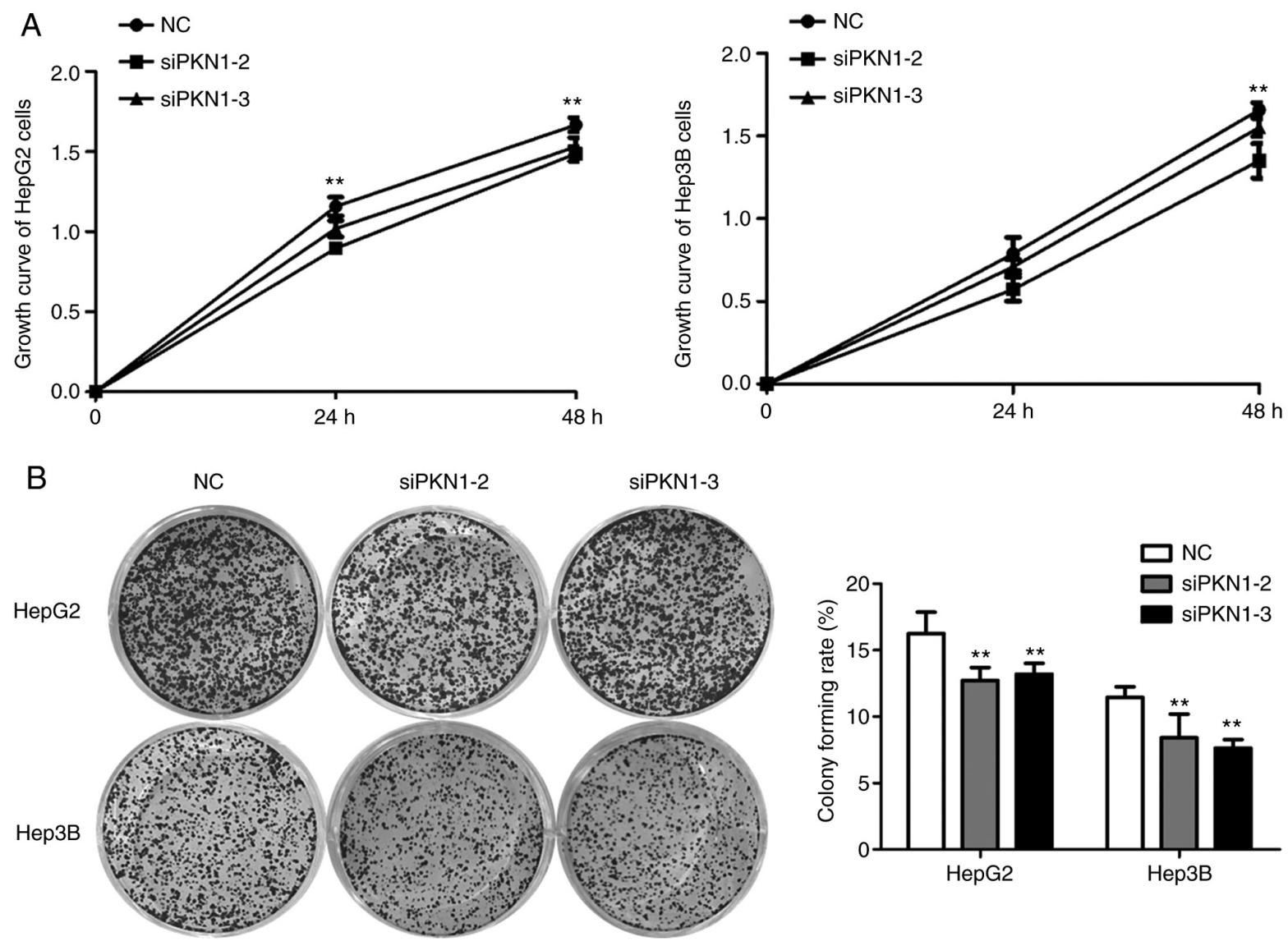

Figure 3. Downregulated PKN1 expression suppresses proliferation of liver cancer cells. Silencing PKN1 inhibited proliferation of liver cancer cells. (A) Proliferation curve was generated according to optical density of proliferative cells at 0,24 and $48 \mathrm{~h}$ after PKN1 transfection. (B) Colony forming ability was suppressed when cells were cultured for 10 days after transfection and stained with $0.1 \%$ crystal violet. ${ }^{* *} \mathrm{P}<0.01$. PKN1, protein kinase N1; NC, negative control; si, short interfering.

MVD marked with CD34 in moderately and poorly differentiated HCC was significantly higher compared with highly differentiated HCC. However, no definite correlation was found between MVD and VEGF in HCC.

Ki67 proliferation index reflects the degree of tumor proliferation, which is significantly correlated with tumor doubling time (32). In the present study, the Ki67 index in moderately and poorly differentiated HCC was also significantly higher compared with highly differentiated HCC, which was positively correlated with PKN1 expression. The above immunohistochemical results suggested that PKN1 served a role in promoting angiogenesis and proliferation of HCC.

Invasion, metastasis, proliferation and apoptosis of tumor cells are important biological indicators of malignant tumor cells. Previous studies have validated the roles of PKN1 in promoting the progression of endometrial and prostate cancer cells and malignant melanoma cells $(15,18,19)$. HepG2 and Hep3B cells have beencultured as liver cancer cells for studies on biological and pharmaceutical properties of liver cancer $(1,33)$. In vitro, it was found that migration and invasion of liver 
A

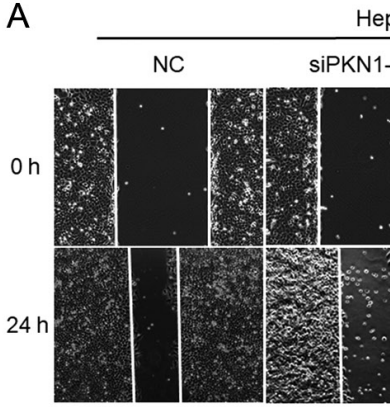

HepG2

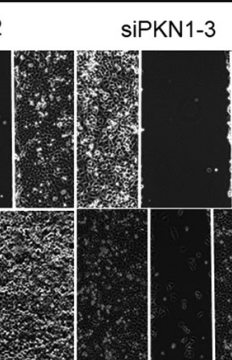

-

Hep3B

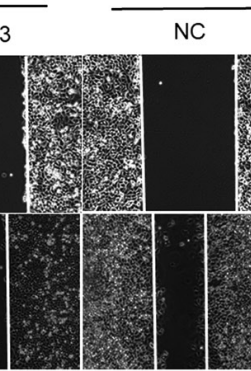
siPKN

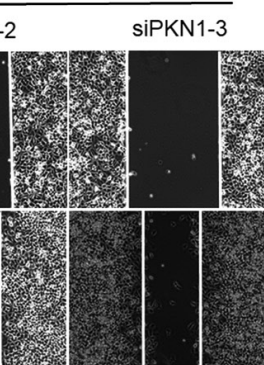

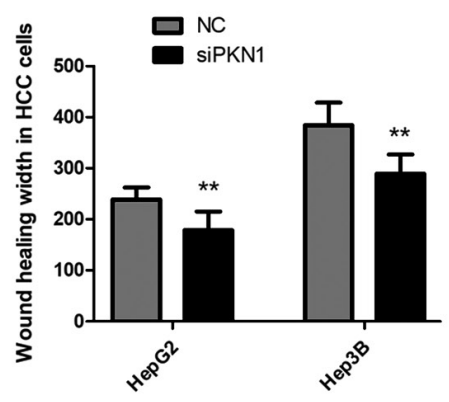
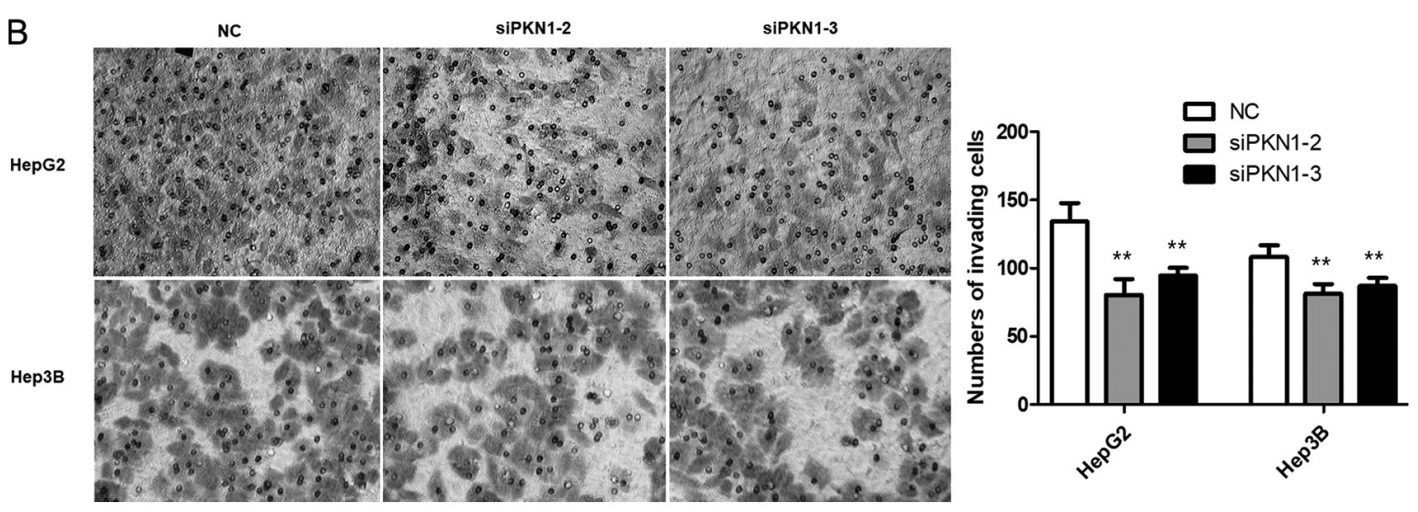

Figure 4. Downregulated PKN1 expression inhibits migration and invasion of liver cancer cells (original magnification, x100). (A) Wound scratch assay revealed that cell healing ability in siPKN1 group was significantly slower than the NC group. (B) Transwell invasion assay demonstrated that downregulation of PKN1 significantly reduced invasion of liver cancer cells across the Matrigel (original magnification, $\mathrm{x} 400$ ). ${ }^{* *} \mathrm{P}<0.01$. PKN1, protein kinase N1; si, short interfering; $\mathrm{NC}$, negative control.
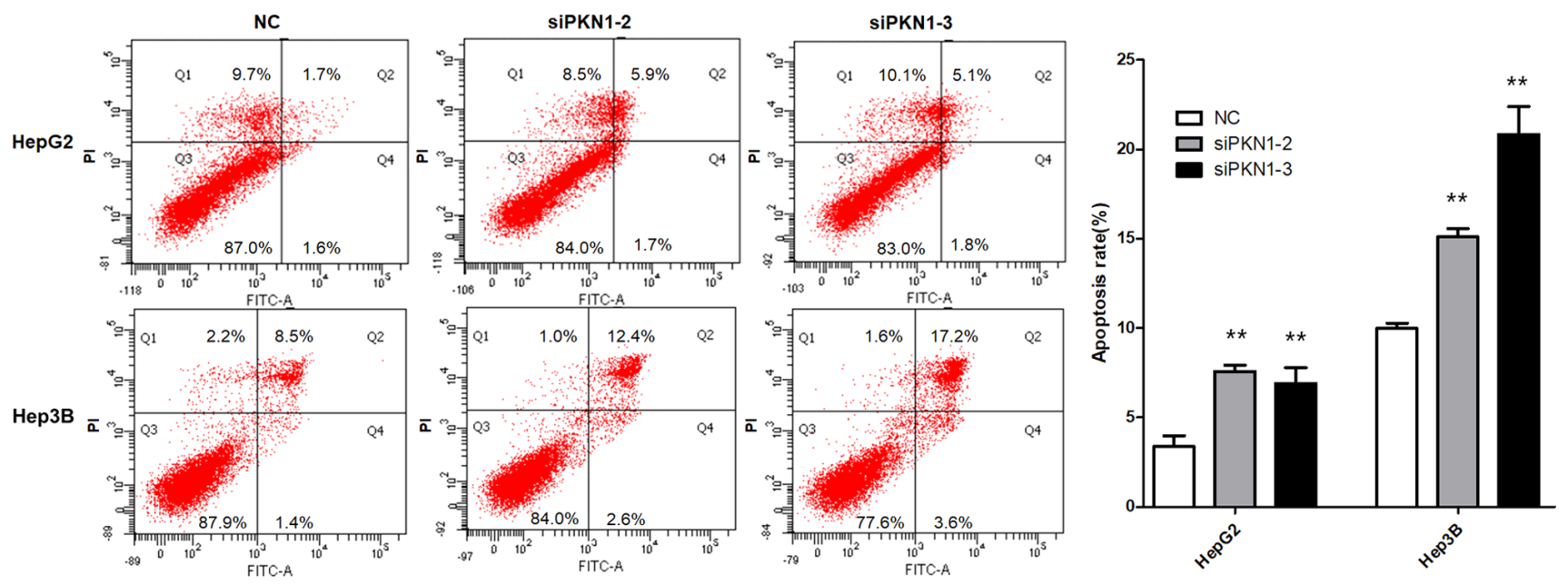

Figure 5. Downregulated PKN1 expression enhances apoptosis of liver cancer cells. Flow cytometry was used to analyzed apoptosis rate of HepG2 and Hep3B cells, including Q4 (early apoptosis) and Q2 (late apoptosis). The results demonstrated apoptosis was promoted when PKN1 was silenced compared with the NC groups. ${ }^{* *} \mathrm{P}<0.01$. PKN1, protein kinase $\mathrm{N} 1$; NC, negative control; si, short interfering.

cancer cells were significantly inhibited when PKN1 expression was silenced compared with the NC group. As described earlier, the catalytic region at the carboxyl end of PKN1 is 50\% homologous to members of the PKC family and once PKN1 is switched, the signaling pathways such as TGF- $\beta / E G F$, PI3K/AKT/mTOR and Wnt $/ \beta$-catenin are activated $(15,18)$. Downstream effects of PKN1 and signaling pathways had been shown to be important in some cancer types $(17,18)$ and it is hoped to explore the mechanism of PKN1 in HCC in follow-up experiments. PKN1 is also an effector molecule of Ras homolog gene family, member A (RhoA)/Ras-related C3 botulinum toxin substrate 1 (RAC1) and mediates cell migration by phosphorylating cytoskeleton organization proteins. PKN1 phosphorylation/activation may be involved in the regulation of endothelial cell proliferation and migration; two events that are essential for angiogenesis (34-36).

The imbalance between apoptosis and cell proliferation contributes to tumor formation and progression. Previous studies have shown that PKN1 has a cleavage site of caspase-3 and is hydrolyzed into $55-\mathrm{kD}$ kinase protein by caspase- 3 and apoptotic protease, which strengthens the activity of PKN1 (37-39). However, Koh et al (40) report that PKN2 
suppresses the antiapoptotic activity of AKT by blocking the phosphorylation of Thr308, Ser473 and its downstream target protein BAD. Tofacitinib, as an inhibitor of JAK1 and JAK3, has been approved for the treatment of rheumatoid arthritis and myeloproliferative diseases. Inhibiting JAK function has been shown to efficiently prevent the uncontrolled growth of cancerous cells (41). Previous studies also suggest that JAK1-3 inhibitor tofacitinib and analogs potently blocks PKN1 activity for the treatment of cancer as well as immune-mediated diseases $(42,43)$. The present study demonstrated that cell proliferation decreased and apoptosis of liver cancer cells increased significantly when PKN1 expression was silenced. In other words, inhibition of PKN1 may inhibit proliferation and increase apoptosis of tumor cells, thus inhibiting tumor growth. The in vitro experiments suggested that PKN1 served a role as an oncogene in the development and progression of liver cancer, which is consistent with the immune response results in clinical studies of liver cancer. Future experiments will be performed to observe the PKN1 gene therapeutic effect in vivo using a liver cancer transplantation model.

In conclusion, PKN1 was highly expressed in HCC clinical specimens and was positively correlated with $\mathrm{HCC}$ histological grading, Ki67 expression and MVD. When the expression of PKN1 is silenced, apoptosis is enhanced and proliferation, migration and invasiveness of liver cancer cells are decreased.

\section{Acknowledgements}

The authors would like to thank Professor Shuhua Wu, Miss Yingying Han and Miss Yangyang Li (Binzhou Medical University Hospital, Binzhou, China). In addition, the authors would like to thank the teachers of the Medical Research Centre of Binzhou Medical University (Yantai, China).

\section{Funding}

Professor Peiyuan Wang was supported by the Natural Science Fund of Shandong Province (grant no. ZR2018MH034).

\section{Availability of data and materials}

All data generated or analyzed during this study are included in this published article.

\section{Authors' contributions}

PW and XW designed the research. XW, YG, MS and HD performed the research. WL and PW analyzed the data. PW and XW drafted the manuscript, and confirmed the authenticity of all the raw data. All authors read and approved the final manuscript.

\section{Ethics approval and consent to participate}

All experimental protocols involving human tissue samples were approved by the Ethics Committee of Binzhou Medical University (Yantai, China; approval no. 2018-012). The patients provided written informed consent.

\section{Patient consent for publication}

Not applicable.

\section{Competing interests}

The authors declare that they have no competing interests.

\section{References}

1. Xie L, Dai H, Li M, Yang W, Yu G, Wang X, Wang P, Liu W, $\mathrm{Hu} \mathrm{X}$ and Zhao M: MARCH1 encourages tumour progression of hepatocellular carcinoma via regulation of PI3K-AKT- $\beta$-catenin pathways. J Cell Mol Med 23: 3386-3401, 2019.

2. Torre LA, Bray F, Siegel RL, Ferlay J, Lortet-Tieulent J and Jemal A: Global cancer statistics, 2012. CA Cancer J Clin 65: 87-108, 2015.

3. Bray F, Ferlay J, Soerjomataram I, Siegel RL, Torre LA and Jemal A: Global cancer statistics 2018: GLOBOCAN estimates of incidence and mortality worldwide for 36 cancers in 185 countries. CA Cancer J Clin 68: 394-424, 2018.

4. Syed YY: Ramucirumab: A review in hepatocellular carcinoma. Drugs 80: 315-322, 2020.

5. Cui H, Dai G and Guan J: Programmed cell death protein-1 (PD-1)-targeted immunotherapy for advanced hepatocellular carcinoma in real world. Onco Targets Ther 13: 143-149, 2020.

6. Kirstein MM and Wirth TC: Multimodal treatment of hepatocellular carcinoma. Internist (Berl) 61: 164-169, 2020 (In German).

7. Metzger E, Yin N, Wissmann M, Kunowska N, Fischer K, Friedrichs N, Patnaik D, Higgins JM, Potier N, Scheidtmann KH, et al: Phosphorylation of histone H3 at threonine 11 establishes a novel chromatin mark for transcriptional regulation. Nat Cell Biol 10: 53-60, 2008.

8. Jilg CA, Ketscher A, Metzger E, Hummel B, Willmann D, Rüsseler V, Drendel V, Imhof A, Jung M, Franz H, et al: PRK1/PKN1 controls migration and metastasis of androgen-independent prostate cancer cells. Oncotarget 5: 12646-12664, 2014.

9. Mukai H: The structure and function of PKN, a protein kinase having a catalytic domain homologous to that of PKC. J Biochem 133: 17-27, 2003.

10. Dong LQ, Landa LR, Wick MJ, Zhu L, Mukai H, Ono Y and Liu F: Phosphorylation of protein kinase $\mathrm{N}$ by phosphoinositide-dependent protein kinase-1 mediates insulin signals to the actin cytoskeleton. Proc Natl Acad Sci USA 97: 5089-5094, 2000.

11. Yasui T, Sakakibara-Yada K, Nishimura T, Morita K, Tada S, Mosialos G, Kieff E and Kikutani H: Protein kinase N1, a cell inhibitor of Akt kinase, has a central role in quality control of germinal center formation. Proc Natl Acad Sci USA 109: 21022-21027, 2012.

12. Lachmann S, Jevons A, De Rycker M, Casamassima A, Radtke S, Collazos A and Parker PJ: Regulatory domain selectivity in the cell-type specific PKN-dependence of cell migration. PLoS One 6: e21732, 2011.

13. Cuny GD: Kinase inhibitors as potential therapeutics for acute and chronic neurodegenerative conditions. Curr Pharm Des 15: 3919-3939, 2009.

14. Galgano MT, Conaway M, Spencer AM, Paschal BM and Frierson HF Jr: PRK1 distribution in normal tissues and carcinomas: Overexpression and activation in ovarian serous carcinoma. Hum Pathol 40: 1434-1440, 2009.

15. Attarha S, Saini RK, Andersson S, Mints M and Souchelnytskyi S: PKN1 modulates TGF $\beta$ and EGF signaling in HEC-1-A endometrial cancer cell line. Onco Targets Ther 7: 1397-1408, 2014.

16. Zeng R, Wang Z, Li X, Chen Y, Yang S and Dong J: Cyclin-dependent kinase 1-mediated phosphorylation of protein kinase N1 promotes anchorage-independent growth and migration. Cell Signal 69: 109546, 2020.

17. Deaton RA, Su C, Valencia TG and Grant SR: Transforming growth factor-beta1-induced expression of smooth muscle marker genes involves activation of PKN and p38 MAPK. J Biol Chem 280: 31172-31181, 2005.

18. Yang CS, Melhuish TA, Spencer A, Ni L, Hao Y, Jividen K, Harris TE, Snow C, Frierson HF, Wotton D and Paschal BM: The protein kinase $\mathrm{C}$ super-family member $\mathrm{PKN}$ is regulated by mTOR and influences differentiation during prostate cancer progression. Prostate 77: 1452-1467, 2017. 
19. James RG, Bosch KA, Kulikauskas RM, Yang PT, Robin NC, Toroni RA, Biechele TL, Berndt JD, von Haller PD, Eng JK, et al: Protein kinase PKN1 represses Wnt/ $\beta$-catenin signaling in human melanoma cells. J Biol Chem 288: 34658-34670, 2013.

20. Park BV, Gaba RC, Huang YH, Chen YF, Guzman G and Lokken RP: Histology of hepatocellular carcinoma: Association with clinical features, radiological findings, and locoregional therapy outcomes. J Clin Imaging Sci 9: 52, 2019.

21. Zhou L, Rui JA, Zhou WX, Wang SB, Chen SG and Qu Q: Edmondson-Steiner grade: A crucial predictor of recurrence and survival in hepatocellular carcinoma without microvascular invasion. Pathol Res Pract 213: 824-830, 2017.

22. Livak KJ and Schmittgen TD: Analysis of relative gene expression data using real-time quantitative PCR and the 2(-Delta Delta C(T)) method. Methods 25: 402-408, 2001

23. Faivre S, Rimassa L and Finn RS: Molecular therapies for HCC: Looking outside the box. J Hepatol 72: 342-352, 2020.

24. Jonas S, Bechstein WO, Steinmüller T, Herrmann M, Radke C, Berg T, Settmacher U and Neuhaus P: Vascular invasion and histopathologic grading determine outcome after liver transplantation for hepatocellular carcinoma in cirrhosis. Hepatology 33: 1080-1086, 2001.

25. Zhou L, Rui JA, Wang SB, Chen SG and Qu Q: Clinicopathological predictors of poor survival and recurrence after curative resection in hepatocellular carcinoma without portal vein tumor thrombosis. Pathol Oncol Res 21: 131-138, 2015.

26. Zhang W, Kim R, Quintini C, Hashimoto K, Fujiki M, Diago T, Eghtesad B, Miller C, Fung J, Tan A, et al: Prognostic role of plasma vascular endothelial growth factor in patients with hepatocellular carcinoma undergoing liver transplantation. Liver Transpl 21: 101-111,2015.

27. Raoul JL and Edeline J: Systemic treatment of hepatocellular carcinoma: Standard of care in China and elsewhere. Lancet Oncol 21: 479-481, 2020

28. Tong X, Wang Q, Wu D, Bao L, Yin T and Chen H: MEK inhibition by cobimetinib suppresses hepatocellular carcinoma and angiogenesis in vitro and in vivo. Biochem Biophys Res Commun 523: 147-152, 2020.

29. Berretta M, Cobellis G, Franco R, Panarese I, Rinaldi B, Nasti G, Di Francia R and Rinaldi L: Features of microvessel density (MVD) and angiogenesis inhibitors in therapeutic approach of hepatocellular carcinoma (HCC). Eur Rev Med Pharmacol Sci 23: 10139-10150, 2019.

30. Mukai H, Muramatsu A, Mashud R, Kubouchi K, Tsujimoto S, Hongu T, Kanaho Y, Tsubaki M, Nishida S, Shioi G, et al: PKN3 is the major regulator of angiogenesis and tumor metastasis in mice. Sci Rep 6: 18979, 2016.

31. Santel A, Aleku M, Röder N, Möpert K, Durieux B, Janke O, Keil O, Endruschat J, Dames S, Lange C, et al: Atu027 prevents pulmonary metastasis in experimental and spontaneous mouse metastasis models. Clin Cancer Res 16: 5469-5480, 2010.
32. Stroescu C, Dragnea A, Ivanov B, Pechianu C, Herlea V, Sgarbura O, Popescu A and Popescu I: Expression of p53, Bcl-2, VEGF, Ki67 and PCNA and prognostic significance in hepatocellular carcinoma. J Gastrointestin Liver Dis 17: 411-417, 2008.

33. Xie L, Li M, Liu D, Wang X, Wang P, Dai H, Yang W, Liu W, $\mathrm{Hu} \mathrm{X}$ and Zhao M: Secalonic Acid-F, a novel mycotoxin, represses the progression of hepatocellular carcinoma via MARCH1 regulation of the PI3K/AKT/ $\beta$-catenin signaling pathway. Molecules 24: 393, 2019.

34. Turner EC, Kavanagh DJ, Mulvaney EP, McLean C, Wikström K, Reid HM and Kinsella BT: Identification of an interaction between the TPand TP isoforms of the human thromboxane $\mathrm{A} 2$ receptor with protein kinase C-related kinase (PRK) 1. Implications for prostate cancer. J Biol Chem 286: 15440-15457, 2011.

35. Owen D, Lowe PN, Nietlispach D, Brosnan CE, Chirgadze DY, Parker PJ, Blundell TL and Mott HR: Molecular dissection of the interaction between the small $\mathrm{G}$ proteins Racl and RhoA and protein kinase C-related kinase 1 (PRK1). J Biol Chem 278: 50578-50587, 2003.

36. Modha R, Campbell LJ, Nietlispach D, Buhecha HR, Owen D and Mott HR: The Racl polybasic region is required for interaction with its effector PRK1. J Biol Chem 283: 1492-1500, 2008.

37. Takahashi M, Mukai H, Toshimori M, Miyamoto M and Ono Y: Proteolytic activation of PKN by caspase 3 or related protease during apoptosis. Proc Natl Acad Sci USA 95: 11566-11571, 1998.

38. Ueyama T, Ren Y, Sakai N, Takahashi M, Ono Y, Kondoh T, Tamaki N and Saito N: Generation of a constitutively active fragment of PKN in microglia/macrophages after middle cerebral artery occlusion in rats. J Neurochem 79: 903-913, 2001.

39. Cryns VL, Byun Y, Rana A, Mellor H, Lustig KD, Ghanem L, Parker PJ, Kirschner MW and Yuan J: Specific proteolysis of the kinase protein kinase C-related kinase 2 by caspase 3 during apoptosis. Identification by a novel, small pool expression cloning strategy. J Biol Chem 272: 29449-29453, 1997.

40. Koh H, Lee KH, Kim D, Kim S, Kim JW and Chung J: Inhibition of Akt and its anti-apoptotic activities by tumor necrosis factor-induced protein kinase C-related kinase 2 (PRK2) cleavage. J Biol Chem 275: 34451-34458, 2000

41. Aittomäki S and Pesu M: Therapeutic targeting of the Jak/STAT pathway. Basic Clin Pharmacol Toxicol 114: 18-23, 2014.

42. Ostrovskyi D, Rumpf T, Eib J, Lumbroso A, Slynko I, Klaeger S, Heinzlmeir S, Forster M, Gehringer M, Pfaffenrot E, et al: Tofacitinib and analogs as inhibitors of the histone kinase PRK1 (PKN1). Future Med Chem 8: 1537-1551, 2016.

43. Hosseini A, Gharibi T, Marofi F, Javadian M, Babaloo Z and Baradaran B: Janus kinase inhibitors: A therapeutic strategy for cancer and autoimmune diseases. J Cell Physiol 235: 5903-5924, 2020. 